Harvard Kennedy School Misinformation Review ${ }^{1}$

October 2020, Volume 1, Issue 6

Creative Commons Attribution 4.0 International (CC BY 4.0)

Reprints and permissions: misinforeview@hks.harvard.edu

DOI: https://doi.org/10.37016/mr-2020-44

Website: misinforeview.hks.harvard.edu

\title{
Overcoming resistance to COVID-19 vaccine adoption: How affective dispositions shape views of science and medicine
}

Health experts worry that a COVID-19 vaccine boycott could inhibit reaching "herd immunity," and their concerns have only grown as the pandemic has spread. Concern has largely focused on anti-vaccine protestors, who captured headlines as they stood side by side with Tea Party activists and armed militia groups demonstrating against the quarantine in April and May of this year. But anti-vax extremists make up only about a third of respondents in surveys who said they would not vaccinate. Health officials must also take into account a swelling group who may understand the importance of a vaccine but are hesitant and confused because they feel the vaccine's development is being rushed and may not be safe or effective. The challenge for the public health community is complex; it has to fashion messages to a set of disparate groups, each employing a unique set of biases when processing information about the efficacy of getting a vaccination.

Authors: John E. Newhagen (1), Erik P. Bucy (2)

Affiliations: (1) Philip Merrill College of Journalism, University of Maryland, USA, (2) College of Media and Communication, Texas Tech University, USA

How to cite: Newhagen, J., \& Bucy, E. (2020). Overcoming resistance to COVID-19 vaccine adoption: How affective dispositions shape views of science and medicine. Harvard Kennedy School (HKS) Misinformation Review, 1(6).

Received: June 15 ${ }^{\text {th }}, 2020$. Accepted: September 22 ${ }^{\text {nd }}, 2020$. Published: October $23^{\text {rd }}, 2020$.

\section{Research questions}

- Do affective dispositions, including warmth or coolness toward social actors and institutions and feelings of social trust, better explain anti-vax attitudes than political ideology or demographics?

- Are there underlying commonalities in the worldview of respondents who say they will not use a COVID-19 vaccine and those who reported voting for Donald Trump in 2016?

- Can the collective of single-issue activists referred to as the anti-vaxxer community, who embrace misinformation and conspiracy, be understood in the broader context of their affective dispositions toward social actors and institutions?

- Are traditional, information-based public service announcements (PSAs) or similar appeals likely to be effective in reaching everyone who says they will not vaccinate, or is a more nuanced approach required?

\footnotetext{
${ }^{1}$ A publication of the Shorenstein Center for Media, Politics and Public Policy, at Harvard University, John F. Kennedy School of Government.
} 


\section{Essay summary}

- This study is based on the analysis of two surveys: The first was executed by the Winton Centre for Risk and Evidence Communication at the University of Cambridge and probed attitudes toward the risk of the novel coronavirus (University of Cambridge, 2020). Data from the United States (N $=700$ ) were collected on March 19, 2020, at the height of the pandemic's first wave. The second $(\mathrm{N}=3,000)$ was fielded as part of the 2018 American National Election Study Pilot study (ANES, 2018), which was conducted just before the 2018 midterm congressional elections.

- Conservative survey respondents appear more likely to align themselves with the anti-vax movement, which supports oppositional readings of public health expert advice, whereas liberal respondents place more trust in science and medicine but express some doubt about vaccinating and might be described as hesitant.

- However, ideology does not fully explain vaccine resistance. Factor analysis of anti-vaxxer trust scores shows some commonalities among liberal and conservative skeptics. In particular, vaccine want-nots show a high level of distrust for dissimilar social groups (immigrants and people who speak other languages), not unlike the populist attitudes that drive support for Donald Trump.

- The model of information reception implied by the growing divide in vaccination attitudes and the underlying commonalities between vaccine want-nots across ideological differences is one of emotional disposition rather than rational deliberation, where the two key affective orientations to the pandemic are denial and alarm.

\section{Implications}

The deaths of over 210,000 Americans and hospitalization of President Trump for complications arising from COVID-19 has brought the severity of the ongoing pandemic into stark relief. Eight months after the World Health Organization declared a global pandemic, coronavirus infections continue to surge around the world (Times, 2020). Public health experts see the rapid development of a vaccine as key to stemming the pandemic. Yet, they acknowledge that resistance to using a new vaccine could thwart that effort (PBS News Hour, 2020). Multiple national surveys fielded during the first wave of the COVID-19 pandemic in the spring of 2020 showed that $20 \%$ to $30 \%$ of respondents said they would not get a vaccine when one becomes available (AP-NORC, 2020; Goldstein \& Clement, 2020; Thigpen \& Funk, 2020). By September, that number had risen to nearly $50 \%$ (Tyson et al., 2020).

The task at hand is to better understand the complexity of those survey respondents who say they do not intend to get vaccinated. The anti-vax movement is the most visible contingent of resistance to using a vaccine. The movement bases its claims about the dangers of vaccines for highly infectious diseases, such as measles and mumps, on misinformation, flawed science, and conspiracy theories (Johnson et al., 2020). One claims billionaire philanthropist Bill Gates plans to insert tiny microchips in the yet-to-be developed vaccine that will enable him to track the movement of billions of people (Strauss, 2020). Movement activists have appeared regularly at protests to lift quarantine lockdown measures.

Positioning the anti-vax movement ideologically is not a straightforward exercise. On the surface, it is not apparent what protestors against a COVID-19 vaccine have in common with the agendas of other objectors such as militia members, restaurant and bar owners, media conspiracists and conservative operatives, who argue against public health lockdowns (Bogel-Burroughs, 2020). At first glance, the antilockdown protests from last spring seemed like a hodgepodge of disgruntled activists, with no common values between them. Anti-vaxxers were protesting a vaccine that did not yet exist, while other groups had more immediate agendas about freedom of movement and commerce. 
Yet, distrust of establishment actors and policies that would restrict protestors' way of life seemed central. Indeed, our analysis reveals that social trust plays a pivotal role and the attitudinal underpinnings of COVID-19 anti-vaxxers' beliefs are similar to those embracing right-wing ideology and who report voting for Donald Trump in 2016. This similarity between groups, registers, somewhat surprisingly, on unrelated questions concerning distrust of immigrants and people who speak other languages. Intolerance, and lack of openness to difference, form a connective sinew.

The two datasets analyzed for this study provide snapshots of social and political attitudes in the U.S. just before the 2018 midterm elections and at the height of the pandemic's first wave in mid-March 2020. The surveys contain similar banks of affective questions asking respondents to rate their feelings toward polarizing social groups and institutions, as well as trust in fact-based processes (e.g., science, medicine, and journalism). The 2018 ANES study also asked who the respondent voted for in the 2016 presidential election, and the 2020 Cambridge survey included a question about potential use of a COVID-19 vaccine (see Appendix 2 \& 3).

The Cambridge data show that anti-vaxxers are likely to call themselves "to the far right" politically and score lower on social trust questions than those who express a willingness to vaccinate. Anti-vaxxers also score lower on trust for science and mainstream journalism than those who say they will vaccinate. The ANES data show the same pattern for social attitudes, political conservatism, and voting for Donald Trump.

Factor analysis of social trust items in the Cambridge data yielded a liberal dimension made up of trust for science, medicine, and journalists while also loading on trust for people who speak different languages and immigrants. While scores on this factor clearly represent the expected underlying attitudes of antivaxxers toward science and medicine, the presence of questions about immigrants and those who speak a different language is less obvious.

One explanation can be found in Ludwig Wittgenstein's theory of family resemblance (Wittgenstein, 1953/2010). He argues that things that could be connected by one essential common feature may in fact be connected by a series of overlapping similarities, where no one feature is common to all of the items in the set. Wittgenstein gave the example of a large family portrait where a resemblance can be seen, but a unifying feature among family members is not obvious.

In the case of protest groups with seemingly disparate goals, such as anti-vaxxers and gun rights activists, each group may focus on a fairly narrow set of beliefs. Distrust of science and medical research are shared outlooks among anti-vaxxers. However, variables concerning immigrants and people who speak another language overlap with these attitudes and with broader support for Donald Trump. One way to think about the array of right-wing groups in the opinion sphere is to imagine them sharing a fundamental distrust and ill will toward what they perceive to be the mainstream opinion agenda. Stuart Hall (1980) observed that individuals who distrust the mainstream agenda may adopt "oppositional readings" of media messages. Such counterarguing not only rejects intended meanings but, in the case of vaccinations, could open the door to embracing misinformation and conspiracy well outside the mainstream as an alternative.

The idea of dissonant groups with unique agendas grounded in the same baseline distrust for information coming from professionals such as doctors, scientists, or journalists can be modeled on a gradient descent terrain map. Used as a visualization tool in neural net modeling, gradient descent is an iterative optimization algorithm for finding a local minimum on a multidimensional contour. The algorithm moves along a fairly smooth contour toward a stable "solution." Figure 1 illustrates the contour represents a right-wing dispositional outlook driven by skepticism of establishment views and low social trust. Specific groups, such as anti-vaxxers, are represented by local "maxima," or peaks that pop-up from the base contour. These represent hotspots corresponding to a particular interest. The red peak in the illustration might represent anti-vaxxers. Other peaks could represent interest groups, such as Flat Earth 
believers or QAnon supporters, also sharing the base belief system. The unifying key to the model is that all the peaks and valleys share a common baseline belief system.

While the thrust of this article has to do with vaccine adoption, these results hint at a nuanced understanding of fringe group coincidence that begins with a common embrace of misinformation and conspiracy to fuel movement growth and goes beyond simple categorizations based on political ideology and demographics.

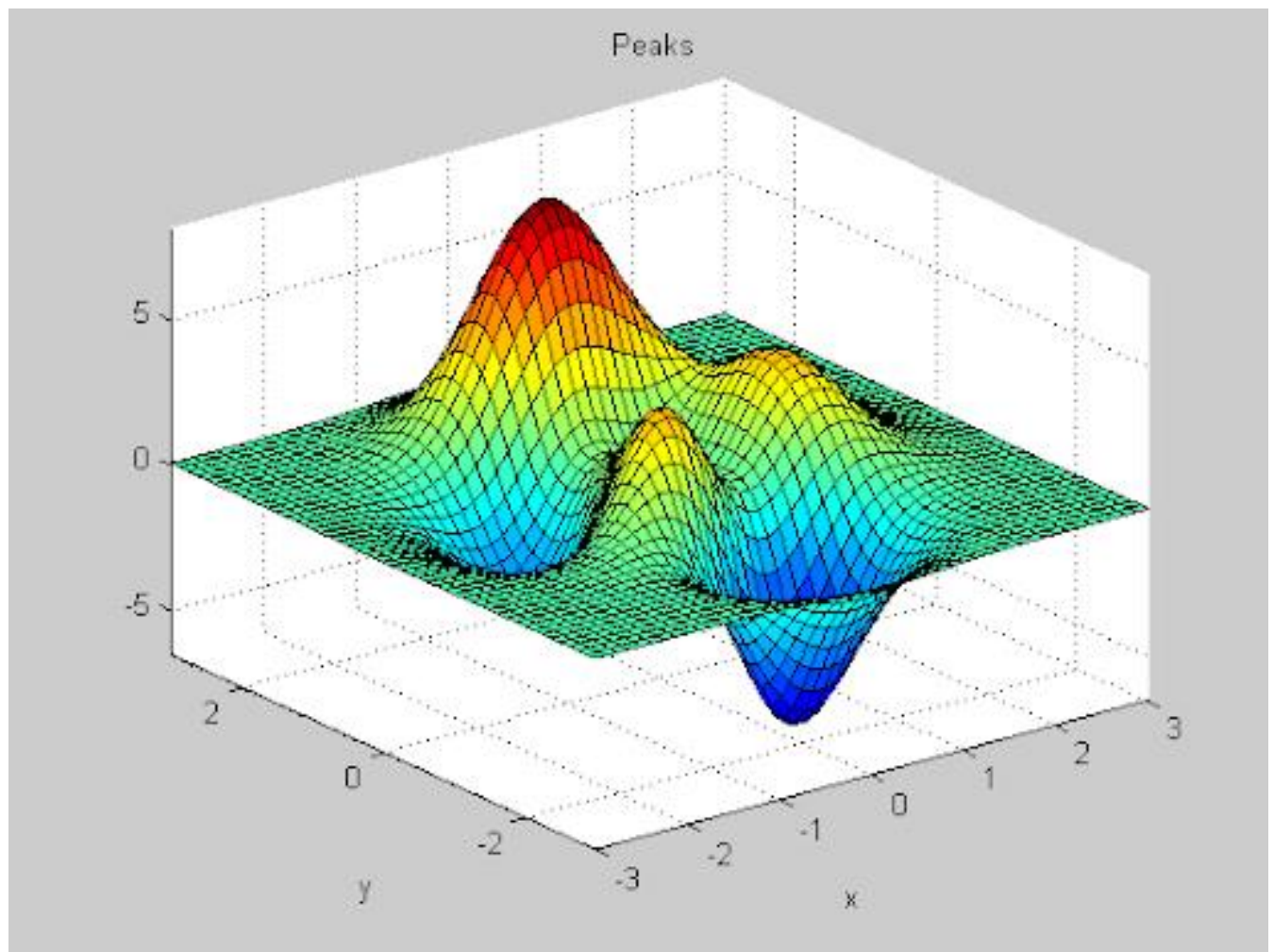

Figure 1. Dissonant belief system visualized as gradient descent graphic. Adapted from Dr. Ali Haydar Özer, Marnara University (annotated).

\section{Findings}

To better understand the affective component of resistance toward using a COVID-19 vaccine, data from two national surveys are analyzed and compared:

Finding 1: The prominence of anti-vax protestors in anti-lockdown demonstrations suggested those opposed to a vaccine share a right-wing ideological orientation along with other protest groups. However, Table 1 shows only slightly over a third of self-identifying conservatives qualify as anti-vaxxers.

Political ideology is associated with intention to use a COVID-19 vaccine $(\chi 2=38.6, p<.0001)$. Among those reporting "no," ideological orientation is evenly distributed. $37.06 \%$ of these respondents identify as ideologically left, followed by $35.88 \%$ on the right. The remaining $27.06 \%$ are in the center. The $24.25 \%$ of all respondents who said they would not get the vaccine is a number already large enough to raise concern about reaching herd immunity. This invites questions about what motivates those in the center and left who do not intend to vaccinate. 
Neither age, gender, education, nor race (measured as belonging to a minority group) were strongly associated with intention not to get a COVID-19 vaccination.

Table 1. Contingency analysis of ideology by intention to use a COVID-19 vaccine (Cambridge data).

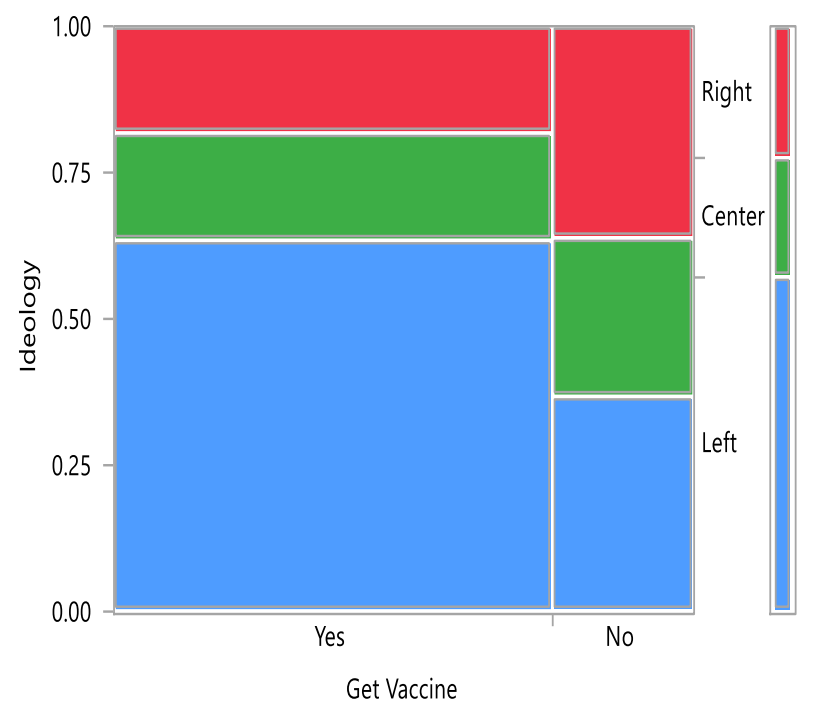

\begin{tabular}{|c|c|c|c|c|}
\hline $\begin{array}{c}\text { Count } \\
\text { Total \% } \\
\text { Col \% } \\
\text { Row \% }\end{array}$ & Left & Center & Right & Total \\
\hline & 338 & 97 & 96 & \\
Yes & 48.22 & 13.84 & 13.69 & \\
& 84.29 & 67.83 & 61.15 & 531 \\
& 63.65 & 18.27 & 18.08 & 75.75 \\
\hline \multirow{3}{*}{ No } & 63 & 46 & 61 & \\
& 8.99 & 6.56 & 8.70 & \\
& 15.71 & 32.17 & 38.85 & 170 \\
& $\mathbf{3 7 . 0 6}$ & $\mathbf{2 7 . 0 6}$ & $\mathbf{3 5 . 8 8}$ & $\mathbf{2 4 . 2 5}$ \\
\hline Total & 401 & 143 & 157 & \\
& 57.20 & 20.40 & 22.40 & 701 \\
\hline
\end{tabular}

Finding 2: Feelings and trust for a wide range of polarizing actors and institutions grouped well into three dimensions of a factor analysis. Responses to questions about political figures and institutions formed one dimension. Responses to questions concerning emotion toward scientists and journalists, and their work, grouped together in a second factor. Neither of those outcomes was unexpected. However, the fact that feelings toward immigrants and people who speak foreign language are part of both the social trust and the trust in science dimensions suggests a shared opinion structure between the two that is based on assessments of "others," or out groups. This is important, because it shows that anti-vax attitudes have a deep connection with other fringe groups that embrace misinformation and conspiracy.

Respondents were asked how much they trusted a number of social groups, as well as government and scientific institutions. To tease out differences in anti-vax attitudes between ideological groups a set of questions asking respondents to rate their trust in a number of social, scientific, and government indicators was factor analyzed. Table 2 shows that three robust factors emerged: one loading on social trust items, one on trust in science, and one on trust in local government (see red highlights).

- Factor 1. Social Trust: Eigenvalue 5.17, explaining 27.4\% of total variance, included measures of general social trust, and trust of strangers, people who speak different languages, immigrants, neighbors, co-workers and fellow students, family, and journalists.

- Factor 2. Trust in Science: Eigenvalue 1.76, explaining 22\% of total variance, included measures of trust for scientists, scientific knowledge, medical doctors and nurses, journalists, people who speak different languages, and immigrants.

- Factor 3. Trust in Government: Eigenvalue 1.3, explaining 14.1\% of total variance, included measures of trust for the government where you live, and politicians. The factor loading on trust in science is especially interesting because it includes items for trust in immigrants and trust for those who speak a different language. 
Table 2. Factor analysis of social, scientific, and government indicators.

\begin{tabular}{|c|c|c|c|}
\hline \multicolumn{5}{|c|}{ Rotated Factor Loading } \\
\hline Variables & $\begin{array}{c}\text { Social } \\
\text { Trust }\end{array}$ & $\begin{array}{c}\text { Trust in } \\
\text { Science }\end{array}$ & $\begin{array}{c}\text { Trust in } \\
\text { Government }\end{array}$ \\
\hline Trust Strangers & 0.797286 & 0.059172 & 0.116659 \\
\hline Trust Different Language & 0.755641 & 0.329333 & -0.094418 \\
\hline Trust Immigrants & 0.722443 & 0.376565 & -0.110753 \\
\hline General Social Trust & 0.709443 & 0.129178 & 0.262824 \\
\hline Trust Neighbors & 0.701216 & 0.142160 & 0.267937 \\
\hline Trust Work or Study & 0.645135 & 0.228602 & 0.243558 \\
\hline Trust Family & 0.368910 & 0.238493 & 0.251904 \\
\hline Trust Scientists & 0.164670 & 0.900750 & 0.002561 \\
\hline Trust Science Knowledge & 0.129642 & 0.882848 & 0.014697 \\
\hline Trust Medical & 0.249857 & 0.737654 & 0.214256 \\
\hline Trust Journalists & 0.336077 & 0.557036 & 0.059749 \\
\hline Trust Local Government & 0.115648 & -0.019167 & 0.895522 \\
\hline Trust Politicians & 0.181195 & 0.135672 & 0.831309 \\
\hline
\end{tabular}

Finding 3: Trust in science is high for those on the ideological left who say they will get a vaccination. Trust is somewhat lower for those who say they will not get a vaccination. Both curves steadily decrease to their lowest level for right-wing ideology. This suggests ideology does make a difference for trust in science.

An index variable, named "Trust in Science," was created by summing the variables that loaded on Factor 2. Figure 2 shows main effects for that index with political ideology $(F=17.7, p<.0001)$ and intention to get a COVID-19 vaccination $(F=30.4, p<.0001)$.

Trust in science is lower for those who say they will not get a vaccination than those that say they will regardless of ideological orientation. 


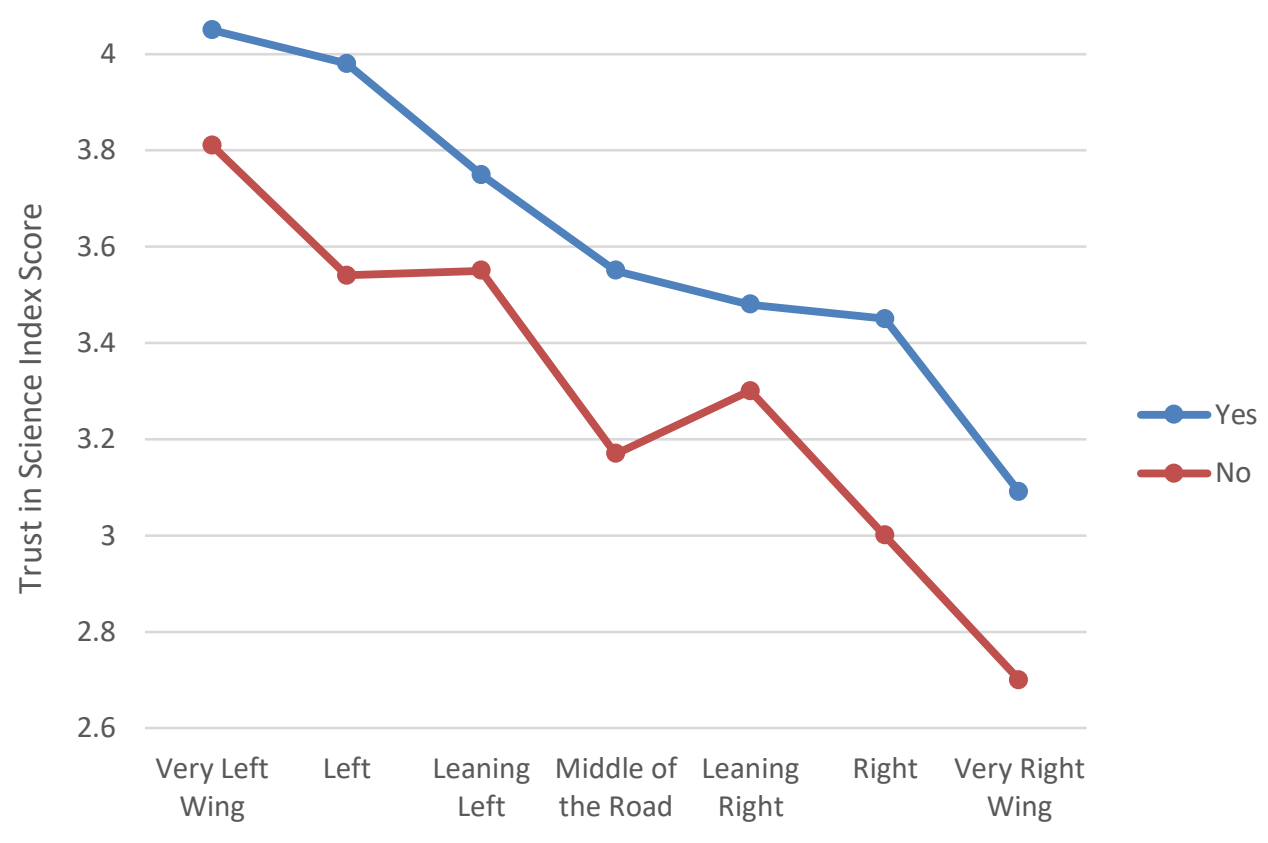

Political Ideology

Figure 2. Trust in Science Index by ideology and intention to use a COVID-19 vaccine (Cambridge data).

Finding 4: Affective assessments of polarizing social groups and individuals proved to be robust predictors of presidential voting in 2016 and intention to get a COVID-19 vaccine. Those assessments outperformed demographics (age, gender, and education) and political ideology.

Figure 3 shows neural network analysis from ANES data of respondents' feelings toward 18 different polarizing social actors, professions, and institutions (e.g., blacks, gays, immigrants, journalists, the police, the Supreme Court, the alt. right). The analysis produced a robust solution, correctly predicting voting in 2016 with more than $90 \%$ accuracy (generalized $\mathrm{R}^{2}=.847$ ). By contrast, using age, gender, and race as the input vector variables predicted voting about $50 \%$ of the time. 


\begin{tabular}{|l|c|c|c|}
\hline \multicolumn{4}{|c|}{ Confusion Rates } \\
\hline \multirow{3}{*}{ Actual Rate } & \multicolumn{3}{|c|}{ Predicted Rate } \\
\cline { 2 - 4 } & $\mathbf{2 0 1 6}$ Vote & Trump & Clinton \\
\cline { 2 - 4 } & Trump & 0.934 & 0.066 \\
\cline { 2 - 4 } & Clinton & 0.075 & 0.925 \\
\hline
\end{tabular}

Generalized $R^{2}=0.71$

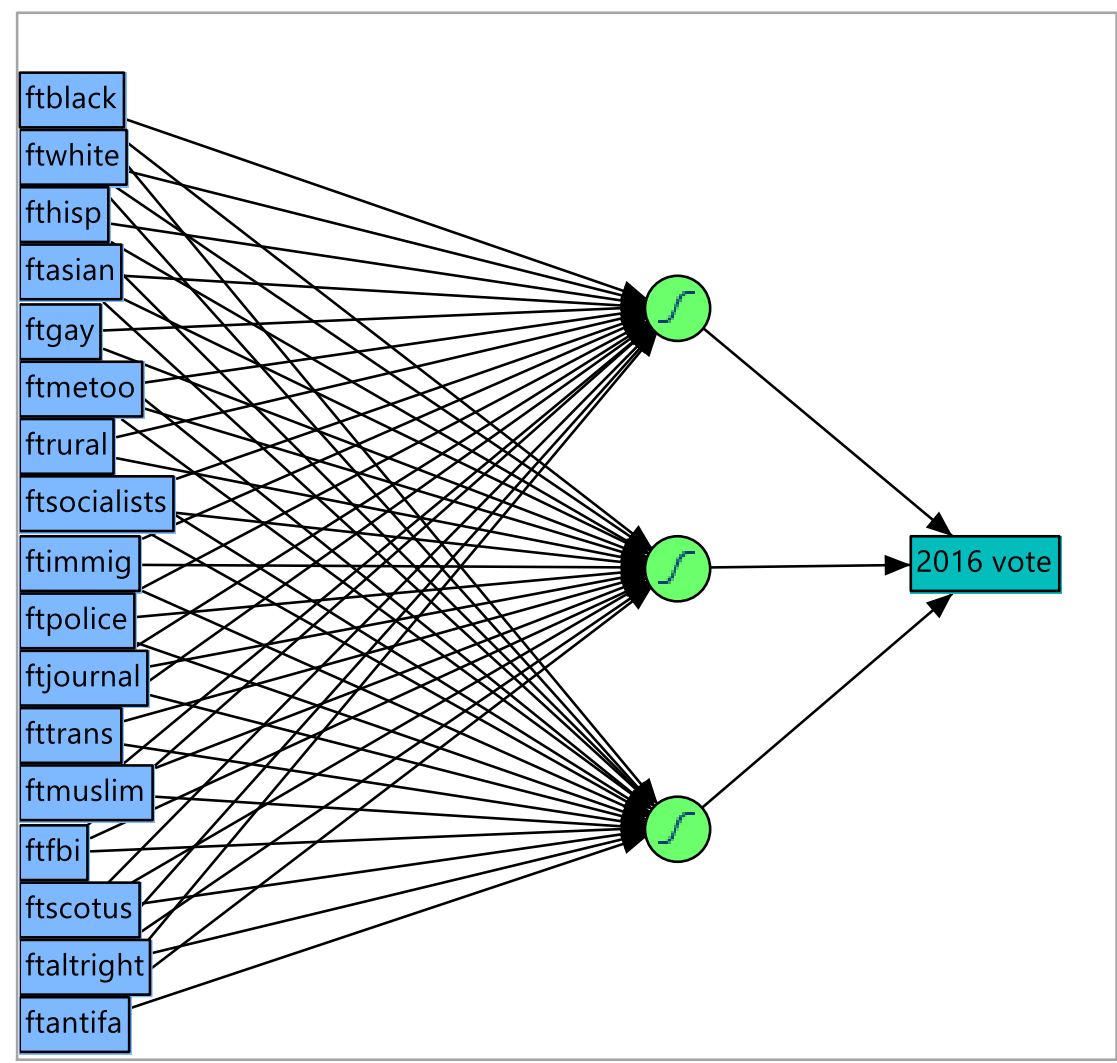

Figure 3. Three-layer neural network analysis of respondent feelings toward different polarizing social actors, professions, and institutions.

Finding 5: Both datasets fielded a battery of questions meant to gauge feelings about and trust toward social actors and groups. While the two data sets are independent, the similarity of liking curves between 2016 Presidential voting and 2020 intent to get a Covid-19 vaccine is notable.

ANOVA results for the 2018 ANES data showed that voting for Trump was associated with lower thermometer ratings for feelings toward Muslims, immigrants, journalists, and trust in media.

ANOVA findings from the Cambridge data showed an association between anti-vaccination attitudes and significantly lower trust scores compared to those who said they would vaccinate. This finding held for general social trust, immigrants, strangers, co-workers and fellow students, family, and journalists. These trends also held for trust in doctors and nurses, scientists, and scientific knowledge. For tabular details of specific ANOVA tests for both datasets, see Appendix 1.

Figures 4 and 5 show that the slopes response curves for both sets of trust and liking variables are nearly identical, where voting for Trump and not wanting a COVID-19 vaccination associate with unfavorable views of outgroups. 


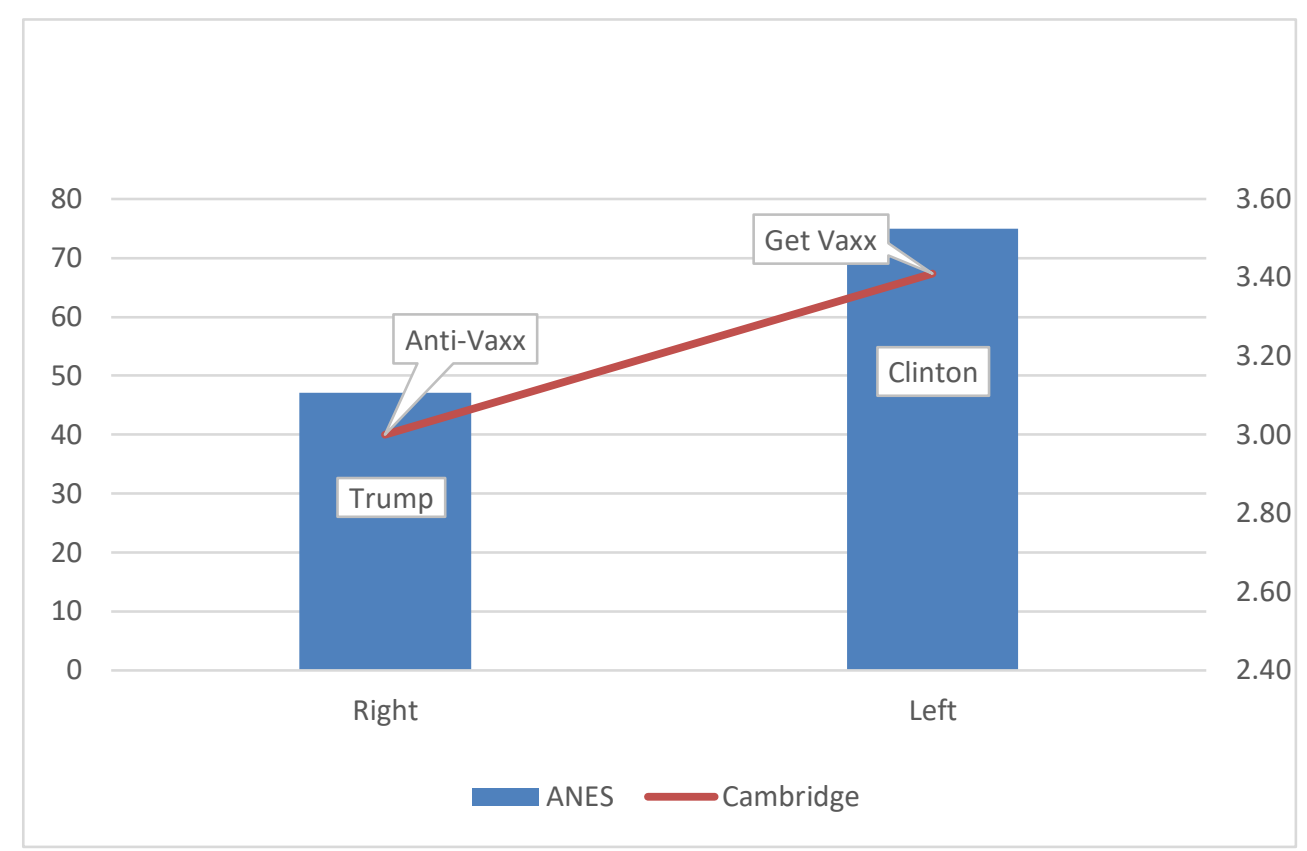

Figure 4. Feelings toward immigrants by ideology, 2016 Presidential vote, and intent to get COVID-19 vaccine.

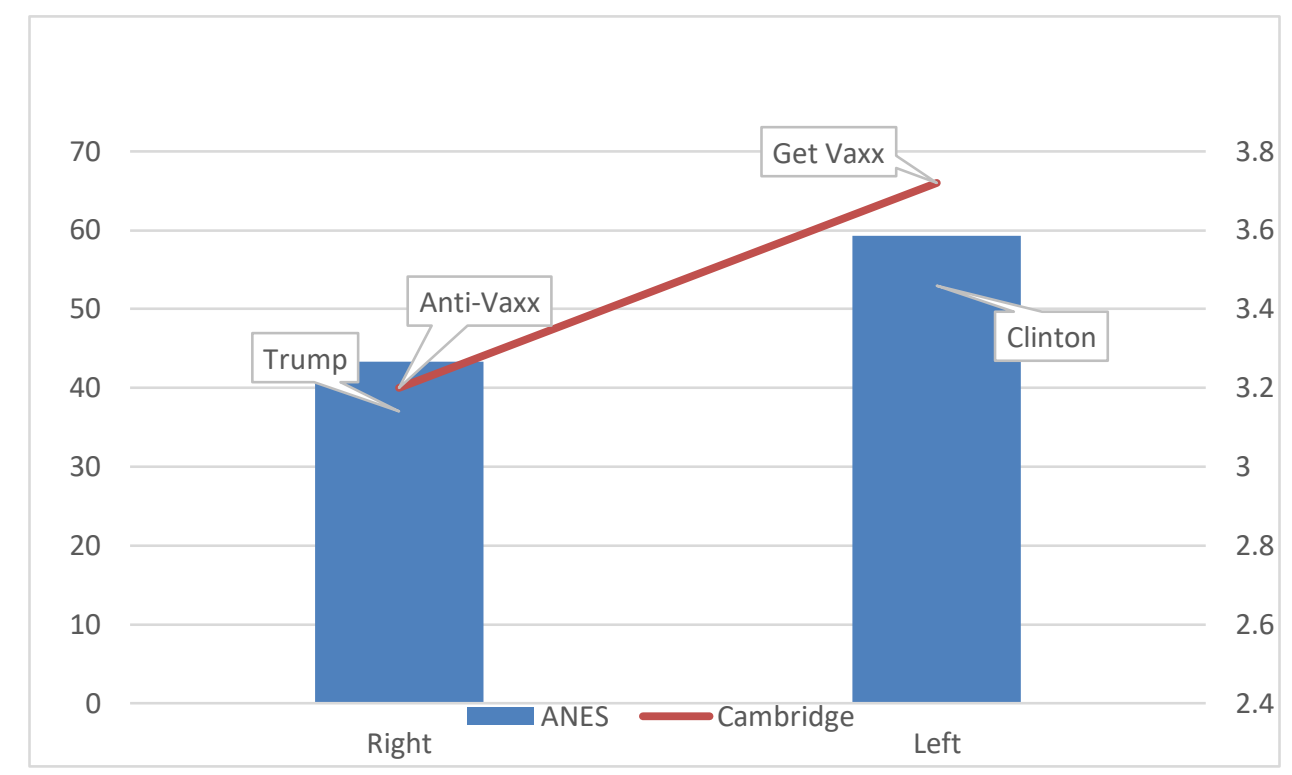

Figure 5. Feelings toward people who speak another language by ideology, 2016 presidential vote, and intent to get COVID19 vaccine.

Finding 6: Analysis of affective assessments of polarizing groups and individuals suggests that those planning on forgoing a vaccination are best described by differing dispositional styles-ways of engaging with issues that have important implications for how different groups process information.

One group fits the mold of the anti-vax movement, where misinformation (many times fake science) and conspiracy trump mainstream science and medicine. The other group is more apt to accept science but may be hesitant to adopt a vaccine in its early stages of development. A fundamental view of the world based on the affective acceptance (or rejection) of "others" may drive dispositional worldviews. 
Finding 7: Taken together, the findings of this study suggest emotion play important roles in the processing of misinformation and conspiracy. At a basic emotional level dispositional groups appear to be driven by anger and fear, which manifest itself in virus-related behaviors is driven by denial and alarm.

These responses occur within an increasingly distorted and fractured media ecology characterized by hyper-polarization, where preferred information channels act as preprocessing filters to organize information into ideologically familiar frames. Denialists, who make up most of Trump's core, rely heavily on false or misleading information as the foundation for their worldview. Analysis here supports the notion that this group generally distrusts and has colder emotional feelings toward outside groups. Alarmists, on the other hand, rely on fact-based information and take rational action, but pay such close attention to public affairs that they may routinely experience fear in response.

\section{Methods}

This analysis is based on a survey executed by the Winton Centre for Risk and Evidence Communication at the University of Cambridge (University of Cambridge, 2020). It probed attitudes toward the risk of coronavirus. Data from the United States were collected on March 19, 2020, at the height of the pandemic's first wave. The survey $(N=700)$ is representative of national census data by age, gender, and ethnicity. Participants were recruited through the online platform Prolific.co. The margin of error of $\pm 4 \%$, assuming the sample is representative. See Appendix 2 for actual question wording.

Data from the American National Election Study (ANES) Pilot $2018(N=3,000)$ also are examined (ANES, 2018). That survey was conducted just before the 2018 midterm congressional elections. It is based on a YouGov Internet-based panel. The panel consists of a large and diverse set of over 1 million respondents who volunteer to complete surveys online and who regularly receive invitations to do so. See Appendix 3 for a list of question wording.

\section{Bibliography}

American National Election Studies. (2018). Codebook and user's guide to the ANES 2018 Pilot Study. https://electionstudies.org/wpcontent/uploads/2019/02/anes pilot 2018 userguidecodebook.pdf

AP-NORC. (2020). Expectations for a COVID-19 vaccine. http://www.apnorc.org/projects/Pages/Expectations-for-a-COVID-19-Vaccine.aspx

Bogel-Burroughs, N. (2020, May 2). Anti-vaccination activists are growing force at virus protests. The New York Times. https://www.nytimes.com/2020/05/02/us/anti-vaxxers-coronavirusprotests.html?smid=em-share

Goldstein, A., \& Clement, S. (2020, June 1). 7 in 10 Americans would be likely to get a coronavirus vaccine, Post-ABC poll finds. The Washington Post. https://www.washingtonpost.com/health/7in-10-americans-would-be-likely-to-get-a-coronavirus-vaccine-a-post-abc-pollfinds/2020/06/01/4d1f8f68-a429-11ea-bb20-ebf0921f3bbd story.html

Hall, S. (1980). Encoding/decoding. Culture, media, language: Working papers in cultural studies, 197279 (pp. 128-138). Hutchinson.

Johnson, N. F., Velásquez, N., Restrepo, N. J., Leahy, R., Gabriel, N., El Oud, S., Zheng, M., Manrique, P., Wuchty, S., \& Lupu, Y. (2020). The online competition between pro- and anti-vaccination views. Nature, 582(7811), 230-233. https://doi.org/10.1038/s41586-020-2281-1 
Marcus, G E., Neuman, W. R., \& Mackuen, M. (2000). Affective intelligence and political judgment. University of Chicago Press.

PBS News Hour. (2020, July 17). How Fauci says the U.S. can get control of the pandemic. PBS. https://www.pbs.org/newshour/show/how-fauci-says-the-u-s-can-get-control-of-the-pandemic

Strauss, V. (2020). How the "Plandemic" movie and its falsehoods spread widely online. The Washington Post. https://www.washingtonpost.com/education/2020/04/21/no-bill-gates-did-not-engineercovid-19-pandemic-other-lessons-fake-news/

Thigpen, C. L., \& Funk, C. (2020, May 21). Most Americans expect a COVID-19 vaccine within a year; $72 \%$ say they would get vaccinated. Pew Research Center. https://www.pewresearch.org/facttank/2020/05/21/most-americans-expect-a-covid-19-vaccine-within-a-year-72-say-they-wouldget-vaccinated/

Tyson, A., Johnson, C., \& Funk, C. (2020, Sept. 17). U.S. public now divided over whether to get COVID-19 vaccine. Pew Research Center: Science \& Society. https://www.pewresearch.org/science/2020/09/17/u-s-public-now-divided-over-whether-toget-covid-19-vaccine/

University of Cambridge. (2020). Winton Centre survey on how people are responding to the communications around COVID-19. Winton Centre for Risk and Evidence Communication. https://wintoncentre.maths.cam.ac.uk/news/winton-centre-survey-how-people-areresponding-communications-around-covid-19/

Wittgenstein, L. (2010/1953). Philosophical investigations. John Wiley \& Sons. 


\section{Funding}

No external funding.

\section{Competing interests}

No potential conflicts of interest.

\section{Ethics}

No institutional review board or ethics committee for human or animal experiments review required.

\section{Copyright}

This is an open access article distributed under the terms of the Creative Commons Attribution License, which permits unrestricted use, distribution, and reproduction in any medium, provided that the original author and source are properly credited.

\section{Data availability}

Codebook and User's Guide to the ANES 2018 Pilot Study

https://electionstudies.org/wp-content/uploads/2019/02/anes pilot 2018 userguidecodebook.pdf

Winton Centre survey on how people are responding to the communications around COVID-19 https://wintoncentre.maths.cam.ac.uk/news/winton-centre-survey-how-people-are-respondingcommunications-around-covid-19/ 


\section{Appendix 1: Analysis of variance for feeling and trust ratings}

ANES 2018 Pilot: Feelings and trust ratings on topical themes

(Feelings rated on 100-degree thermometer, Trust rated on five-point scale, where $1=$ None, 5= A Great Deal)

\begin{tabular}{|lc|c|c|c|}
\hline Topic & Analysis of Variance & Voted for Trump & Voted for Clinton \\
\hline $\begin{array}{l}\text { Feelings } \\
\text { Muslims }\end{array}$ & $\begin{array}{c}F(1,1665)=807, \\
p<.0001\end{array}$ & 36.1 & 71.6 \\
\hline $\begin{array}{l}\text { Feelings toward } \\
\text { immigrants }\end{array}$ & $\begin{array}{c}F(1,1665)=501.78, \\
p<.0001\end{array}$ & 47.4 & 74.95 \\
\hline $\begin{array}{l}\text { Feelings toward } \\
\text { journalists }\end{array}$ & $\begin{array}{c}F(1,1665)=2059.9, \\
p<.0001\end{array}$ & 26.2 & 77.6 \\
\hline Trust in media & $\begin{array}{c}F(1,1665)=2067.3, \\
p<.0001\end{array}$ & 1.55 & 3.61 \\
\hline
\end{tabular}

\section{Cambridge: Trust ratings on science and medicine}

(Trust rated on 5-point scale, where $1=$ Can't be too careful and $5=$ Can be trusted a lot)

\begin{tabular}{|l|c|c|c|}
\hline Topic & Analysis of Variance & COVID-19 Anti-Vax & Get COVID-19 vaccine \\
\hline $\begin{array}{l}\text { Trust in doctors and } \\
\text { nurses }\end{array}$ & $\begin{array}{c}F(1,699)=75.9, \\
p<.0001\end{array}$ & 3.72 & 4.33 \\
\hline $\begin{array}{l}\text { Trust in scientific } \\
\text { knowledge }\end{array}$ & $\begin{array}{c}F(1,699)=47.25, \\
p<.001\end{array}$ & 3.92 & 4.4 \\
\hline Trust in scientists & $\begin{array}{c}F(1,699)=51.61, \\
p<.0001\end{array}$ & 3.79 & 4.3 \\
\hline
\end{tabular}

\section{Cambridge: Trust ratings on topical themes}

(Trust rated on 5-point scale, where $1=$ Can't be too careful and $5=$ Can be trusted a lot)

\begin{tabular}{|l|c|c|c|}
\hline Topic & Analysis of Variance & COVID-19 Anti-Vax & Get COVID-19 vaccine \\
\hline General social trust & $\begin{array}{c}F(1,697)=8.2 \\
p<.004\end{array}$ & 3.68 & 4.1 \\
\hline Trust for immigrants & $\begin{array}{c}F(1,697)=27.1 \\
p<.001\end{array}$ & 3.02 & 3.41 \\
\hline $\begin{array}{l}\text { Trust for people who } \\
\text { speak a different } \\
\text { language } \quad \begin{array}{c}F(1,697)=14.88 \\
p<.001\end{array}\end{array}$ & 3.2 & 3.47 \\
\hline Trust for strangers & $\begin{array}{c}F(1,697)=6.98 \\
p<.001\end{array}$ & 2.42 & 2.64 \\
\hline $\begin{array}{l}\text { Trust for co-workers or } \\
\text { fellow students }\end{array}$ & $\begin{array}{c}F(1,697)=10.38 \\
p<.001\end{array}$ & 3.48 & 3.72 \\
\hline Trust for family & $\begin{array}{c}F(1,697)=4.96 \\
p<.001\end{array}$ & 4.14 & 4.48 \\
\hline
\end{tabular}




\section{Appendix 2: Questions used in the analysis from Cambridge data}

\section{Questions used in the analysis from Cambridge data}

How much do you trust each of the following?

Response to all trust questions rated on a five-point scale, anchored by "Cannot be trusted" to "Can be trusted a lot." Individual items included:

People in your family

People in your neighborhood

People you work or study with

People who speak a different language from you

Strangers

Immigrants

Medical doctors and nurses

Scientists

Journalists

Scientific knowledge

Where do you feel your political views lie on a spectrum of left wing (or liberal) to right wing (or conservative)?

Very left wing/ liberal

Left wing/ liberal

Centre left/ slightly liberal

Middle of the road

Centre right/ slightly conservative

Right wing/ conservative

Very right wing/ conservative

If a vaccine were to be available for the coronavirus/COVID-19 now:

Response set:

Yes

No 


\section{Appendix 3: Questions used in the analysis from ANES data}

Questions used in the analysis from ANES data

Feeling questions were administered on the following thermometer scale:

\section{Click on thermometer to give your rating.}

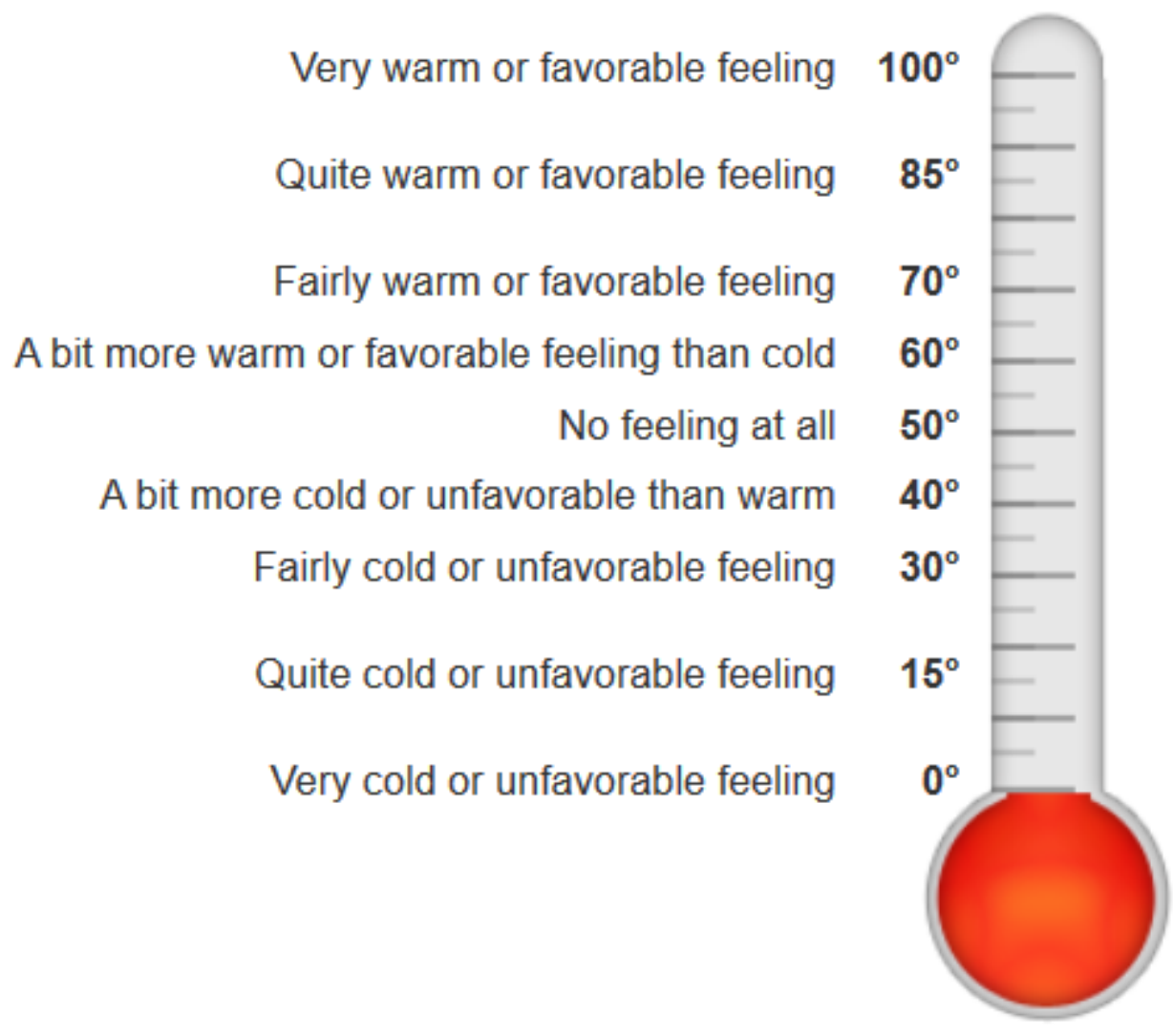

The following items were tested:

How would you rate blacks?

How would you rate whites?

How would you rate Hispanics?

How would you rate Asians?

How would you rate gays and lesbians?

How would you rate immigrants?

How would you rate journalists?

How would you rate transgender people?

How would you rate Muslims?

How would you rate the \#metoo movement?

How would you rate socialists? 
How would you rate the Federal Bureau of Investigation (FBI)?

How would you rate the U.S. Supreme Court?

How would you rate the "alt right"?

How would you rate Antifa?

How would you rate rural people?

In the 2016 presidential election, who did you vote for? Donald Trump, Hillary Clinton, or someone else? Donald Trump

_ Hillary Clinton

_ someone else

When it comes to politics, would you describe yourself, and these groups, as liberal, conservative, or neither liberal nor conservative?

_Very liberal

_. Somewhat liberal

_Closer to liberals

Neither liberal nor conservative

Closer to conservatives

_Somewhat conservative

_ Very conservative 